\title{
Current Conditions and Worker Attitudes in End-of-Life Care for the Elderly in Korea
}

\author{
Masumi Goto ${ }^{1, *}$, Naoko Morita $^{2}$, Fumie Katagiri ${ }^{2}$, Toshiyuki Tsukamoto ${ }^{3}$ \\ ${ }^{1}$ Nursing and Rehabilitation Faculty, Chubu Gakuin University, Japan \\ ${ }^{2}$ Human and Social Services Faculty, Chubu Gakuin University, Japan \\ ${ }^{3}$ Faculty of Nursing and Social Welfare Sciences, Fukui Prefectural University, Yoshida-gun, Japan
}

Copyright $(2015$ Horizon Research Publishing All rights reserved.

\begin{abstract}
Korea has led the way within Asia with its pioneering nursing care insurance system. This study examines the current state of end-of-life care for the elderly, along with future trends, based on surveys and interviews of managers and employees of institutions related to nursing care and nursing care insurance. Korea is seeing a gradual increase in its latter stage elderly population. It naturally follows that this puts pressure on dealing with end-of-life care, and this study revealed concern that the care environment cannot keep pace with the concurrent increase in medical needs. Korea's system restricts end-of-life care to hospital facilities, so care facility staff lack experience and certain kinds of awareness. Workers' own attitudes toward life and death, as well as those toward caring for the sick, influence the quality of end-of-life care. It was found that these attitudes are significantly influenced by religious beliefs and work experience. Social workers had longer experience in caring for the infirm and a stronger tendency to be cognizant of care which focuses on a patient's family. Results indicated that in the future, it will be necessary to consider how care workers can best think about and approach end-of-life care as a team.
\end{abstract}

Keywords Nursing Care Insurance, Elderly, End-of-Life Care, Social Workers, Nurses, Caregivers, Attitude Toward Life and Death, Attitude Toward Care

\section{Introduction}

The elderly population in Korea was determined to be $7.2 \%$ in the year 2000 , then $11.2 \%$ in 2010 . The figure is expected to reach $15.7 \%$ in 2020 . From this point on, it is expected that the problem will accelerate faster than in any other OECD member nation. Meanwhile, the birth rate is rapidly declining, with the total fertility rate hovering between 1.2 and 1.05 since 2000. In terms of population ratios, one can see that the proportion of elderly people is increasing dramatically. Also, the number of single-person households in 2010 was double the approximately 2 million counted in 2000.[1] A sudden increase in demand for care workers due to the rapidly ageing society; an increase in elderly people living alone resulting from factors such as the rise of nuclear families and increased social progress for women; and, a sharp rise in medical costs and the need for long term care associated with an increase in chronic illnesses all became problems.[2] These led to the introduction of a system of long-term care insurance for the elderly (hereafter referred to as "care insurance") in July, 2008. There are a number of similarities between Japan and Korea in terms of the progression of their ageing societies and the decreases in the population of children. So, Korea's care insurance was created with reference to Japan's nursing care insurance system. The two countries have many issues in common, as they share a system of values based on Confucian culture and have accordingly developed care which focuses on families.

Fifteen years have passed since the introduction of care insurance in Japan. In that time, the rapid increase in the later-stage elderly population and in the severity of related problems has continued, leading to the new issue of how to make changes in approaches to end-of-life care. A paper on terminal care for the elderly in Korea was introduced during a seminar held on the "International Comparative Study in Ideal Terminal Care and Death" by the International Longevity Center Japan.[3] However, this did not include any material related to current conditions or attitudes of staff in terminal care facilities for the elderly.

Korea is also exploring for solutions to prepare for its impending super-aging society. There is a need to shed light on current conditions and staff attitudes toward end-of-life care in elderly care facilities. With Korea having been the first in East Asia to introduce care insurance, it is possible to think of Korea and Japan as having a common perspective on these issues. This study seeks to foster mutual understanding by examining issues the two countries have in common.

\section{Materials and Methods}

\subsection{Purpose}


To shed light on conditions in institutions related to end-of-life care for the elderly and attitudes of care staff in Korea, based on interviews and surveys (qualitative and quantitative) with managers and staff, including nurses, care workers, and social workers.

\subsection{Research Design and Methods}

\subsubsection{Current Conditions and Future Direction of Elderly Care in Korea}

Analysis based on statistical data: This study sheds light on relevant issues as perceived through statistical data collected from government sources, sorting out data such as changes in component distribution ratio (percentages) of population, changes in number of households, and details (such as location) of deaths classified by cause of death.

\subsubsection{Qualitative and Quantitative Surveys}

Subjects of interviews and surveys were managers and employees of nursing care and insurance facilities and offices who had obtained permission to participate from facility managers. 215 valid, completed questionnaires were obtained from employees of four facilities in Busan (42 from one care facility and three from the office for home-visit nursing care attached to that facility, and 170 from three medical facilities). Three questionnaires completed by doctors and 22 incomplete questionnaires were excluded from the total collected. Broken down by occupation, there were 70 completed by nurses, 81 by caregivers, 11 by social workers, and 53 by (uncertified) assistants.

\subsubsection{Data Collection Method}

\section{A. Qualitative Survey}

The interviews with managers consisted of questions on the realities of end-of-life care, the future direction of such care, and other relevant points.

\section{B. Quantitative Survey}

The questionnaires for workers sought answers on how individuals in relevant occupations think about end-of-life care, along with questions on views on death and views on care.

Requested data on the respondents themselves consisted of gender, type of work, number of years of experience, religious beliefs, and whether or not they had any experience in end-of-life care. Regarding individuals' ways of thinking, respondents were asked what sort of care they and members of their family would like to receive or provide (and, in cases where they would like to receive end-of-life care, they were asked who they would like to provide that care and what medical treatments they would hope to receive). A death attitude inventory[4] was used to measure feelings and attitudes about life and death. This is an inventory modified for use with Japanese people, and is composed of four questions each on afterlife belief, death anxiety, death relief, death avoidance, life purpose, and death concern, and three questions on supernatural belief (for a total of 27 questions divided into seven categories). A higher score in each section indicates stronger feelings on that section's content. The answer choices for each question range from " 1 . Not true" to "7. True" on a seven point scale. For measuring attitudes on care for the sick and dying, this study employed a linear scale for measuring medical professionals' attitudes on care for terminal patients, in the form of FATCOD-Form B-J (the Japanese version of the Frommelt Attitudes Towards Care of the Dying scale), developed for use with doctors and allied health professionals.[4,5,6,7] This is composed of 30 questions concerning three superordinate concepts related to attitudes on terminal care held by care providers who work with terminal patients and those patients' families. Superordinate concept (I), "positivity of care for patients facing death", is covered by 16 questions concerning such topics as "positive approach to communication with patients facing death", "attitude toward care for patients facing death which is free from fear", and "attitude which finds value in care for patients facing death". Superordinate concept (II), "cognizance of care which focuses on the patient and the family", is covered by 13 questions on such items as "awareness of the need for support from the family for the patient", "attitude of respect for the patient's interests and decision-making", and "way of thinking about care for families". Superordinate concept (III), "way of thinking about death" is addressed by a single question. This study does not endorse the use of this single question which cannot be dealt with as a factor, and so this third superordinate concept was excluded from the results. Responses were chosen from a five point scale: "strongly agree", "agree", "couldn't say either way", "disagree", "strongly disagree". A higher score indicated a more proactive or positive attitude toward terminal care (with half the items inverted).

\subsubsection{Data Analysis Method}

Statistics software SPSS v.11 was used for basic statistical processing of the quantitative survey. For attitudes on life and death and attitudes on care for the sick or dying, Spearman's rank correlation coefficient was calculated after totaling scores for each subscale and factor in the FATCOD-Form B-J. Also, differences in average values for each category of employment were analyzed using t-test.

\subsubsection{Ethical Considerations}

Regarding the goals of the study and the handling of personal information, we explained that no individual's personal information would be specified within the data used, and that no data would be used for any purpose outside of the study goals. We also explained that permission had been obtained from the ethics committees of researchers' affiliated institutions. As for institutions from which permission was obtained, interviews and surveys of staff were conducted after interviews with managers were completed. Interviews began after the subjects had agreed to make an audio recording from which the verbatim interview record would be created. 


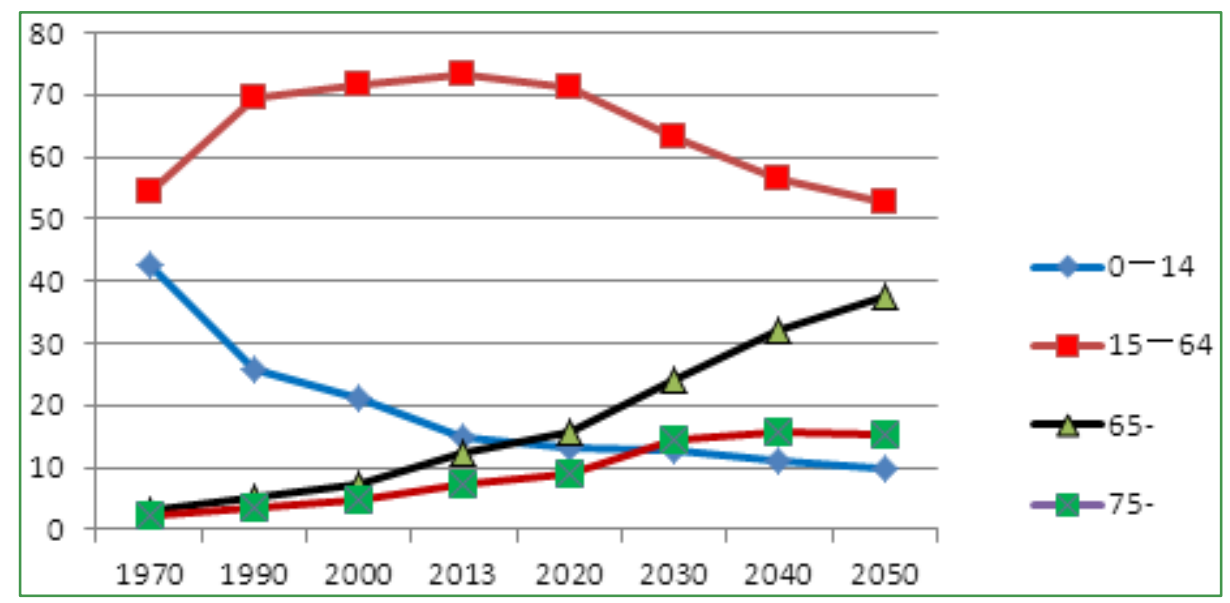

Figure 1. Changes in Demographic Ratios

\section{Results}

\subsection{Statistical Data on Future Directions and Conditions Surrounding Elderly Care in Korea}

Conditions and issues were brought to light through changes in ratios for population (Figure 1), changes in location of death (Table 1), and changes in location of death classified by cause of death, based on demographic statistical data obtained from government sources. Going by population ratios, it is expected that as numbers of latter stage elderly will quickly, incrementally increase beginning in 2020, there will be an increase in deaths and expansion of end-of-life care, thus forcing measures to be taken in terms of end-of-life caregiving. There is concern that if such measures are taken after the aging of society has progressed, those measure will be too late in coming.

Table 1. Changes in Location of Death (2013)

\begin{tabular}{|c|c|c|c|c|c|}
\hline & Home & $\begin{array}{c}\text { Medical } \\
\text { institution }\end{array}$ & $\begin{array}{c}\text { Residential } \\
\text { institution }\end{array}$ & Others & Total \\
\hline 2003 & 42.7 & 45 & 0 & 12.3 & 100 \\
\hline 2009 & 18.8 & 70 & 0.37 & 10.8 & 100 \\
\hline 2010 & 20.3 & 67.7 & 0.33 & 11.8 & 100 \\
\hline 2011 & 19.4 & 68.5 & 0.41 & 12.2 & 100 \\
\hline 2012 & 18.8 & 70.1 & 0.37 & 10.8 & 100 \\
2013 & 17.7 & 71.5 & 3.8 & 7.0 & 100 \\
\hline
\end{tabular}

In Korea, hospitals overtook homes as the more common location for nursing care in 2003. Currently, hospitals (at $71.5 \%)$ outnumber homes $(18.8 \%$ ) as locations for nursing care, yet the nature of those facilities has not changed. The leading causes of death are neoplasms $\left(1^{\text {st }}\right)$ and cardiac disease $\left(2^{\text {nd }}\right)$, with pneumonia and cerebrovascular disease also highly ranked.

Regarding the relationship between cause and location of death, the number of deaths in hospital caused by neoplasms is rising. As for home deaths, there is a trend toward a quite high rate among patients suffering from cardiovascular illnesses (Table 2).

Table 2. Location of Death Classified by Cause of Death (2013)

\begin{tabular}{|c|c|c|c|c|}
\hline & $\begin{array}{c}\text { Medical } \\
\text { institution }\end{array}$ & $\begin{array}{c}\text { Residential } \\
\text { institution }\end{array}$ & Home & Others \\
\hline Neoplasms & 89.2 & 8.5 & 1.1 & 1.2 \\
\hline Cardiac disease & 73.7 & 4.8 & 17.0 & 4.5 \\
\hline $\begin{array}{c}\text { Cerebrovascular } \\
\text { disease }\end{array}$ & 80.6 & 6.6 & 10.7 & 2.1 \\
\hline Pneumonia & 84.1 & 3.6 & 10.3 & 2.0 \\
\hline
\end{tabular}

Compiled by the author based on Korean government statistical data[1]

\subsection{Results of Interviews and Surveys Conducted at Nursing Care Institutions}

\subsubsection{Interview Results (Qualitative Survey)}

Korea's current medical insurance system began in 1989 with the establishment of a national insurance system, which was unified with medical insurance organizations in 2000, then integrated with regional and employment related government funding in 2003. As for medical services, a complete medical system was built through advancement of computerization and planning for raising medical standards focused on private hospitals. The Medical Law stipulates doctors, dentists, doctors of Korean medicine, midwives, and nurses as medical professionals. Nurses are certified by the national government, which preceded Japan in the institution of three- or four-year nursing colleges along with master's and doctoral courses as part of a groundbreaking educational system which actively recruits educators and researchers from the United States. However, there are few certified nurses working in elderly care facilities, which are staffed with a high number of nurse aides and other types of nurses. Nurse aides' education lasts one year, and they play a role similar to that of assistant nurses in Japan. But, they are not legally specified as medical professionals. Also, there are other types of nurses working at medical institutions. These "other nurses" do not legally bear any medical or nursing responsibilities. Having received three days or more of training, they provide medical or convalescent care for 
bedridden elderly persons and are involved in rather specialized patient care.

Social workers' qualifications are graded hierarchically, with those who have graduated university and passed a state examination rated first grade. Most of those who do counseling work are first grade, but there are also those whose employment certification was obtained by completing a course of study which lasts a minimum of twelve weeks. They mainly advise patients and other clients, provide explanations to families and obtain consent, introduce clients to resources, and oversee coordination, among other duties. Social workers sometimes hold an additional post as managers of hospital or other care facilities.

Korea's nursing care insurance system is in full effect, organized into six types of home care services and three types of institutional care services. Institutional care services are allotted to what are known in Japan as special welfare nursing homes for the elderly (hereafter referred to as "welfare facilities"), sanatorium type medical care facilities ("medical facilities"), and daily life group care for the elderly with dementia ("group homes"). There is also money available for family care (in cases where family members act as care workers), a provision which does not exist in the Japanese system.

Also, education for care workers working in the care insurance system has begun, with a first grade curriculum for physical care consisting of 240 hours. The second grade of certification deals with household assistance. At the Busan Visiting Caregiver Association (caregiver dispatch center), there is a system in which care staffers are responsible for the needs of a number of individuals, and are on call 24 hours a day, in order to provide for a stable, healthy lifestyle for elderly persons within regional communities. (In cases where those staffers are unavailable, the system connects the client with an alternate worker through an emergency dispatch number.) Each staffer works four and a half hours a day, five days a week, on a rotation. The work mainly consists of conversation with senior citizens living at home, overseeing their safety, and providing support and advice on lifestyle, exercise, and nutrition. In addition, they introduce resources and coordinate relevant contacts, along with serving as community homemakers, among other roles. Medical facilities deal with those whose problems have become severe, who have recently been treated at university hospitals, and who are suffering from secondary diseases or complications. From 2002-7, there were only 10 such facilities in Busan. That number has reportedly increased to over 70 (with each facility having 100 beds) since the introduction of care insurance. Within the medical system (which has prohibited house calls by doctors since 1977), medical care is carried out exclusively in hospitals. And, since doctors are required to issue death certificates, people living at home or in care facilities are almost always transferred to hospitals when they reach the final stage of life. And yet, clients of care facilities are have become increasingly desirous of end-of-life care. Care facility A, where end-of-life care is possible, has a jointly established clinic with doctors in residence. Care facility B, which is an uncommon example, provides end-of-life care in limited cases in which the desires of the client or family are unambiguous, and in which they are able to obtain the cooperation of doctors at relevant facilities. One unusual characteristic of Korea is that most hospitals contain a funeral home (run by its own staff), allowing for care to extend to funeral services. Since funerals in Korea last three days, it was said that this is highly convenient for families, but that this also leads to hospitals often being short of beds. Just as in Japan, nursing care facilities have clients who require tube feeding or catheters, as well as those who require medical care for serious bed sores, situations in which it is difficult for patients to make their own decisions. On one hand, their families hope for them to have a natural death, while on the other hand, they have strong feelings of filial piety which results in a tendency to ask for proactive, life-extending care. It was stated that this is one reason for clients being transferred to hospitals. Since there are no guidelines for end-of-life care in care facilities, there is a great deal of such proactive, life-extending care in hospitals, and there are legal difficulties involved in ceasing such care once it has begun. There is also a problem in home care situations, with a large number of clients dying alone, so home care staff who visit clients living alone will transfer them to hospitals when their condition becomes serious. At care facility $\mathrm{C}$, doctors form connections with specific communities that they function in, though this arrangement is not officially recognized by the institution.

So, in Korea, there is still little in the way of end-of-life care in institutions within the care insurance system, and there are no guidelines, while the needs of clients are increasing. In the future, they seek more support, from earlier on, for the elderly and their families facing choices about death, along with advanced directives from the individuals themselves. Also, coordination between medical and end-of-life care is indispensible, and future directions taken in end-of-life care are prescribed by the nature of the medical care system. Improvements in policy and support systems are needed in order for people to be able to have the end-of-life care that they want, where they want it, because adaption to changes in the circumstances of elderly peoples' lives is no simple matter.

\subsubsection{Survey Results (Quantitative Survey)}

\section{A. Attributes of Respondents}

Valid responses were collected from 215 individuals. Attributes of respondents are shown in Table 2. Religion is deemed significant, with responses coming from a large number of Buddhists and Christians, but very few non-religious. 85 respondents $(39.5 \%)$ had workplace experience in end-of-life care. Broken down by type of employment, those with workplace experience in caring for the sick were 7 of 11 social workers $(63.6 \%), 40$ of 81 care workers (49.4\%), 25 of 70 nurses (35.7\%), and 13 of 53 assistants (24.5\%). Experience or lack thereof in each type of 
vocation was not statistically significant. Still, there are very few with experience in end-of-life care.

Table 2. Attributes of Respondents

\begin{tabular}{|c|c|c|c|}
\hline \multirow{2}{*}{ Item } & \multirow{2}{*}{ Details } & \multicolumn{2}{|l|}{ Korea } \\
\hline & & Number of People & $\%$ \\
\hline \multirow{2}{*}{ Gender } & Male & 22 & 10.2 \\
\hline & Female & 193 & 89.8 \\
\hline \multirow{4}{*}{ Occupation Type } & Nurse & 70 & 32.6 \\
\hline & Care Worker & 81 & 37.7 \\
\hline & Social Worker & 11 & 5.1 \\
\hline & Nurse Assistant & 53 & 24.7 \\
\hline \multirow{6}{*}{$\begin{array}{c}\text { Years of } \\
\text { Experience }\end{array}$} & Less than 1 & 24 & 11.2 \\
\hline & $1-2$ & 34 & 15.8 \\
\hline & $2-3$ & 29 & 13.5 \\
\hline & $3-5$ & 45 & 20.9 \\
\hline & $5-10$ & 49 & 22.8 \\
\hline & Over 10 & 33 & 15.3 \\
\hline \multirow{3}{*}{ Place of work } & Care Facility & 42 & 19.5 \\
\hline & Medical Facility & 170 & 79 \\
\hline & Home care & 3 & 1.5 \\
\hline \multirow{4}{*}{ Religion } & Buddhism & 78 & 36.3 \\
\hline & Christianity & 72 & 33.5 \\
\hline & Other & 6 & 4.7 \\
\hline & No Religion & 57 & 26.5 \\
\hline \multirow{4}{*}{$\begin{array}{c}\text { Those } \\
\text { experienced in } \\
\text { caring for the sick }\end{array}$} & Nursing & 25 & 35.7 \\
\hline & Care Work & 40 & 49.4 \\
\hline & Social Work & 7 & 63.6 \\
\hline & No Certification & 13 & 24.5 \\
\hline
\end{tabular}

\section{B. Results}

As for desired location of end-of-life care, few would choose family care at home for themselves, with the largest number by far choosing hospitals (Table 3 ). As for by whom they would like to be cared for, $56.3 \%$ chose family, followed by $21.4 \%$ who chose medical personnel (Table 4 ). There was no statistical significance in type of work relative to who and where respondents would choose to receive care. As for desire for measures such as proactive medical care or artificial feeding methods, there was a stronger tendency toward "strongly desire" or "somewhat desire" responses related to what they would choose for family members than when asked what they would choose for themselves (Table $5)$.

Table 3. Preferred Location for Care

\begin{tabular}{|c|c|c|}
\hline & \multicolumn{2}{|c|}{ Location } \\
\hline$\%$ & Family & Self \\
\hline Home & 21.9 & 27.4 \\
\hline Hospital & 47.4 & 46.5 \\
\hline Care Facility & 19.1 & 18.1 \\
\hline Other & 5.1 & 5.6 \\
\hline Unknown & 6.5 & 2.3 \\
\hline & 100.0 & 100.0 \\
\hline
\end{tabular}

Table 4. Preferred Care Providers

\begin{tabular}{|c|c|c|}
\hline & \multicolumn{2}{|c|}{ People to Provide Care } \\
\hline & First Choice & Second Choice \\
\hline Family & 56.3 & 14.4 \\
\hline Friends & 3.7 & 6.0 \\
\hline Medical Personnel & 23.3 & 21.4 \\
\hline Care Workers & 16.3 & 11.2 \\
\hline Others & & 0.5 \\
\hline No Response & 0.5 & 46.5 \\
\hline & 100.0 & 100.0 \\
\hline
\end{tabular}

Table 5. Desired Treatments

\begin{tabular}{|c|c|c|c|c|}
\hline & \multicolumn{4}{|c|}{ Treatment } \\
\hline & \multicolumn{2}{|c|}{$\begin{array}{c}\text { Life-Extending } \\
\text { Treatments }\end{array}$} & \multicolumn{2}{c|}{ Artificial Feeding } \\
\hline$\%$ & Family & Self & Family & Self \\
\hline $\begin{array}{c}\text { Strongly } \\
\text { Desire }\end{array}$ & 4.7 & 3.3 & 4.7 & 1.9 \\
\hline $\begin{array}{c}\text { Somewhat } \\
\text { Desire }\end{array}$ & 22.8 & 7.9 & 38.1 & 14.4 \\
\hline $\begin{array}{c}\text { Somewhat } \\
\text { Not Desire }\end{array}$ & 41.4 & 32.6 & 30.7 & 29.3 \\
\hline No Desire & 20.5 & 47.4 & 18.6 & 47.0 \\
\hline Don't Know & 10.7 & 8.8 & 7.9 & 7.5 \\
\hline & 100 & 100 & 100 & 100 \\
\hline
\end{tabular}

Next is a comparison among different occupations of workers' views on death and caring for the sick. A score for views on death was based on seven factors. For views on care, averages based on overall score and scores for two subscales were calculated, broken down by occupation. The two subscales are: proactive positivity toward care (referred to below as "positivity") and awareness of care focusing on the family (referred to below as "care awareness"). A one-way analysis of variance was conducted for each occupational category, after having tested average values and the difference between those values of the two subscales. This was followed by a multiple comparison test which did not presuppose homogeneity of variance (Tamhane's). No difference in views on death was observed among categories of employment. As for views on care, nurses had a significantly higher general score than uncertified workers (t-test $\mathrm{p}<0.05$ ). Also, social workers scored significantly higher than uncertified workers $(\mathrm{t}-\mathrm{test} \mathrm{p}<0.05)$. Social workers also had a higher general score than all other occupations for care awareness (Table 4).

Years of experience, significance of religion in daily life (hereafter "religious feeling"), and whether or not an individual has experience in caring for the sick were thought to be factors influencing the seven data points for views on death and the two subcategories (positivity and care awareness). The relevance of these factors was analyzed using Spearman's rank correlation coefficient. These factors were seen to have a significant level of $1 \%$, along with the correlation coefficient's absolute value exceeding 0.2 . Among the seven data points for views on death, eight 
correlations were checked, with seven showing a positive correlation. Correlations seen with death avoidance were with fear of death and death as liberation. In contrast, there was indication of a negative correlation between fear of death and sense of purpose in life. Those who fear death avoid thinking about it, and these individuals showed a tendency toward perceiving death as a release from suffering, and toward a having a lower sense of purpose in life. Correlations with death concern were seen in those who view death as a release from suffering and those with higher death avoidance. There was a tendency for these individuals to think about death more often and to be another trend seen was for those who perceive death as a release from suffering and those who avoid death to think about it often and be more accepting of a longer life span. People who were shown to be more accepting of a longer life span tended to believe in an afterlife.

Regarding the relationship between views on care and views on death, a negative correlation was seen between the general score on caring for the sick and death avoidance. The results also confirmed a negative correlation between positivity and both fear of death and death avoidance. Those who showed a strong tendency to fear and avoid thinking about death were seen to remember having difficulties being positive toward patients facing death.

There were connections between religious views, work experience, views on death, and views on care. There was a positive correlation between religious feelings and fear of death, while there was a negative correlation between death as a release and both sense of purpose in life and acceptance of natural lifespan. There was also a tendency for those for whom religion plays only a small role in daily life to fear death and be unable to clearly perceive any meaning or purpose in life. Also, one could see a relationship between experience in caring for the sick or lack thereof and religious feeling. Experience or lack thereof and religious views were predicted as the main factors influencing both views on care and views on death. There was also a significant level of 5\% in the relationship between years of experience and views on care, with those having more years of experience being more positive and proactive in their views on care (Table 5).

Table 4. Differences Between Occupations in Views on Care

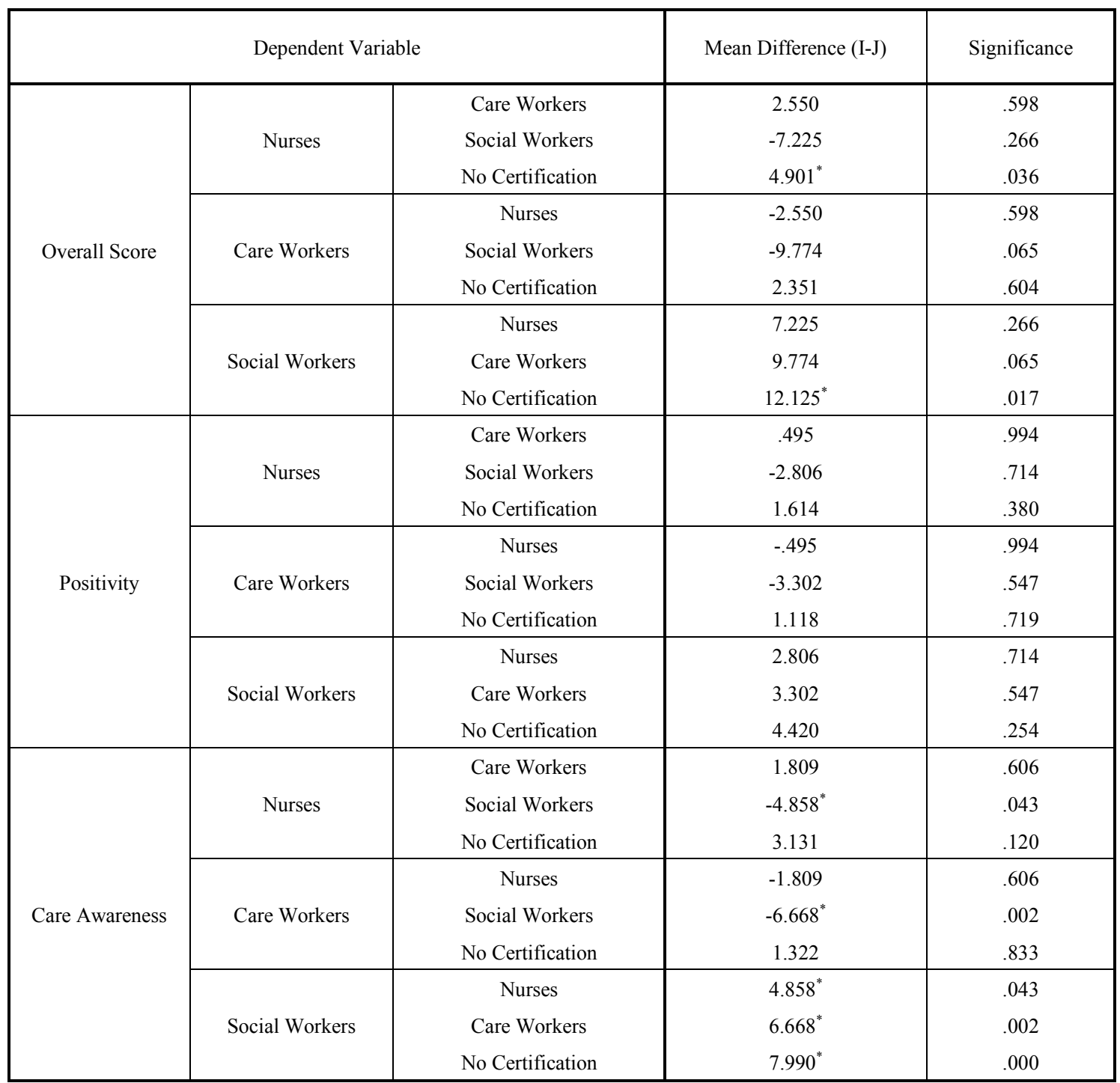


Table 5. Correlations Among Attributes of Views on Death and Care

\begin{tabular}{|c|c|c|c|c|c|c|c|c|c|c|c|c|c|c|}
\hline & & Af'life & Fear & Release & Avoid & Purpose & Conc. & $\begin{array}{c}\text { Natural } \\
\text { Death }\end{array}$ & $\begin{array}{c}\text { General } \\
\text { Score }\end{array}$ & Positi'y & Aware & $\begin{array}{c}\text { Years of } \\
\text { Exp. }\end{array}$ & Religion & Exp. \\
\hline & Afterlife & 1 & & & & & & & & & & & & \\
\hline D & Belief & & & & & & & & & & & & & \\
\hline \multirow{2}{*}{$\begin{array}{l}\mathrm{e} \\
\mathrm{a} \\
\mathrm{t}\end{array}$} & Fear of & $.161^{*}$ & 1 & & & & & & & & & & & \\
\hline & Death & .018 & & & & & & & & & & & & \\
\hline \multirow[t]{2}{*}{ h } & Death as & .133 & .051 & 1 & & & & & & & & & & \\
\hline & Release & .052 & .458 & & & & & & & & & & & \\
\hline \multirow{2}{*}{$\begin{array}{c}\mathrm{A} \\
\mathrm{t}\end{array}$} & Death & .127 & $.617^{* *}$ & $.202^{* *}$ & 1 & & & & & & & & & \\
\hline & Avoidance & .064 & .000 & .003 & & & & & & & & & & \\
\hline \multirow{6}{*}{$\begin{array}{l}\mathrm{t} \\
\mathrm{i} \\
\mathrm{t} \\
\mathrm{u} \\
\mathrm{d} \\
\mathrm{e}\end{array}$} & Life & .133 & $-.180^{* *}$ & .097 & -.106 & 1 & & & & & & & & \\
\hline & Purpose & .052 & .008 & .157 & .120 & & & & & & & & & \\
\hline & Death & $.147^{*}$ & .082 & $.351^{* *}$ & $.179^{* * *}$ & $.158^{*}$ & 1 & & & & & & & \\
\hline & Concern & .032 & .233 & .000 & .009 & .021 & & & & & & & & \\
\hline & Natural & $346^{* *}$ & .066 & $.306^{* *}$ & $.136^{*}$ & .120 & $.314^{* *}$ & 1 & & & & & & \\
\hline & Death & .000 & .334 & .000 & .047 & .079 & .000 & & & & & & & \\
\hline \multirow{6}{*}{$\begin{array}{l}\mathrm{C} \\
\mathrm{a} \\
\mathrm{r} \\
\mathrm{e}\end{array}$} & General & -.056 & -.097 & .059 & $-.301^{* *}$ & .059 & -.124 & $-.162^{*}$ & 1 & & & & & \\
\hline & Score & .418 & .158 & .391 & .000 & .387 & .071 & .018 & & & & & & \\
\hline & I Positivity & -.067 & $-.212^{* *}$ & -.024 & $-.393^{* *}$ & .117 & -.130 & $-.159^{*}$ & $.734^{* *}$ & 1 & & & & \\
\hline & & .325 & .002 & .725 & .000 & .086 & .058 & .020 & .000 & & & & & \\
\hline & II Care & -.010 & .030 & .105 & -.122 & -.016 & -.085 & -.096 & $.860^{* *}$ & $.302^{* *}$ & 1 & & & \\
\hline & Awareness & .890 & .658 & .124 & .073 & .813 & .217 & .161 & .000 & .000 & & & & \\
\hline \multirow{6}{*}{$\begin{array}{l}\mathrm{O} \\
\mathrm{t} \\
\mathrm{h}\end{array}$} & Years of & .044 & -.099 & -.019 & -.089 & $.181^{* *}$ & -.079 & .010 & .131 & $.164^{*}$ & .060 & 1 & & \\
\hline & Experience & .517 & .146 & .778 & .193 & .008 & .250 & .880 & .055 & .016 & .380 & & & \\
\hline & Religious & $-.169^{*}$ & $.216^{* *}$ & $-.201^{* *}$ & $.159^{*}$ & $-.180^{* *}$ & $-.157^{*}$ & $-.295^{* *}$ & -.117 & $-.173^{*}$ & -.038 & -.081 & 1 & \\
\hline & Views & .013 & .001 & .003 & .019 & .008 & .021 & .000 & .087 & .011 & .582 & .238 & & \\
\hline & Experience & -.085 & $.145^{*}$ & -.053 & .065 & .005 & .000 & -.039 & -.085 & -.127 & -.016 & \begin{tabular}{l|}
.022 \\
\end{tabular} & $.200^{* *}$ & 1 \\
\hline & & .216 & .033 & .441 & .346 & .942 & .995 & .567 & .213 & .062 & .812 & .747 & .003 & \\
\hline
\end{tabular}

\subsection{Summary of Results}

- There is a trend in Korea toward moving patients into hospitals as they approach the end of life. Also, larger hospitals contain funeral facilities.

- More training for care workers is needed in order to prepare systems for dealing with elderly people in homes and local communities.

- There is also a trend toward elderly people receiving intensive care or tube feeding even in the final stage of life.

- $\quad$ Nursing care facilities lack experience in end-of-life care for the elderly and rely on hospitals.

- There are no established guidelines for end-of-life care in nursing care facilities.

- There is no difference among occupational types in views on death. However, religion was shown to be a relevant. There was a tendency for those with no religion to fear death.

- Views on care were influenced by length in years of workplace experience or lack thereof.

- Experience or lack thereof and religious views were predicted as the main factors influencing both views on care and views on death. Social workers were shown to have more experience in caring for the sick as well as a significantly higher tendency toward awareness of care which focuses on the family.

\section{Conclusions}

It has been five years since Korea's nursing care insurance began, but this study has identified the situation that measures for dealing with end-of-life care for latter-stage elderly people are still not in hand. Under the present circumstances, Korea's health care system limits end-of-life care to hospitals. Staff at care facilities lack experience, and the way in which medical services are carried out affects awareness. Dr. Lee[8], President of the South Korean Alzheimer's Association, identifies insufficient provisions by local governments for home care, leading in most cases to institutionalization in hospitals for the elderly, as a problem with end-of-life care for those suffering from Alzheimer's.

Korea's elderly population will gradually increase from 2020 on, bringing pressure to bear on measures taken for end-of-life care, and it is feared that the treatment environment will not be up to par as society's medical needs increase along with that population. Whether Korea adapts a policy by which care giving is incorporated into medical treatment or vice-versa, the country will want to pay close 
attention to the future course of government policy on elderly care.

The quality of end-of-life care is influenced by the views on death and care held by the workers themselves.[9] Views on death were greatly influenced by religious views. Also, length of experience and, in some cases, absence of experience in caring for the sick affected views on care. There was a trend by which social workers were shown to have more experience in caring for the sick, and a significantly higher awareness of care which focuses on patients' families. In this survey, the total numbers calculated for the category "nurses" included both nurses and nurse aides. One can assume that this led to there being very little difference in awareness results between nurses and other care workers. There are more nurse aides who have one year of education than there are nurses working, but they are not officially recognized as medical personnel. Also, those who have no nursing certifications were observed caring for severe cases, without any institutionally mandated training. There was a tendency for these uncertified workers to have low general scores for views on care, demonstrating a need for appropriate education and training.

It is easy for those who bear the burdens of end-of-life care to develop a negative attitude toward care when lack of steadfast views on such issues as death and care render them unable to properly face clients. There were indications that opportunities for education in end-of-life care are needed, as the formation of an individual's views on death and care are heavily influenced by that person's religious views and relevant work experience. For the future, it will be necessary to investigate how workers, as a team, can approach end-of-life care.

The International Comparative Study on Ideal Terminal Care and Death indicates that the United Kingdom passed The Mental Capacity Act in 2005. This law does not regulate end-of-life care, but does systematically guarantee the validity of advance directives. Australia has the Guidelines for a Palliative Approach in Residential Aged Care (2006) and the Guidelines for a Palliative Approach for Aged Care in the Community Setting (2011). In Japan, the Japan Geriatrics Society has set forth guidelines on measures for prolonging life. In Korea, as well, the Korean Medical Association has created guidelines relating to the cessation of life extending measures. But, these guidelines have not been codified in any sort of legislation. One can point to the rarity of advance directives in end-of-life care for the elderly, even without considering the importance of the concerned individual's own decisions, as a serious issue common to both countries. It is hoped that in the future, guidelines for providing end-of-life care with dignity will be established, as an extension of nursing care in general.

\section{Acknowledgements}

This research was partially supported by the Grant in Aid for Exploratory Research \#2465314 from the Japan Society for the Promotion of Science.

\section{REFERENCES}

[1] Online Available from e-Stat (portal site of official statistics of Japan), https://www.e-stat.go.jp/SG1/estat/html/GL02100 101.html and KOSIS (Korean Statistical Information Service),

Http://kosis.kr/statisticsList/statisticsList_01List.jsp?vwcd= MT_ZTITLE\&parentId=A

[2] Im Cheon-shik. Organization and Development of Korea's Nursing Care Insurance System, Minerva Shobo, Japan, 2010 .

[3] Online Available from International Longevity Center Japan: http://www.ilcjapan.org/symposiumE/1202.html

[4] K. Hirai, Y. Sakaguchi, K. Abe. The study of death attitude: construction and validation of the death attitude inventory, Japan Journal of Clinical Research on Death and Dying, Vol. 23, No. 1, 71-76, 2000.

[5] Y. Nakai, M. Miyashita, T. Sasahara. Factor structure and reliability of the Japanese version of the Frommelt Attitudes Towards Care of the Dying scale (FATCOD-B-J), Japanese Journal of Oncology Nursing, Vol. 11, No. 6, 723-729, 2006.

[6] L.A. Rooda, R. Clements, M.L. Jordan. Nurses' attitudes toward death and caring for dying patients, Oncology Nursing Forum, Vol. 26, No. 10, 1683-1687, 1999.

[7] K.S. Dunn, C. Otten, E. Stephens. Nursing experience and the care of dying patients, Oncology Nursing Forum, Vol. 32 , No. 1, 97-104, 2005.

[8] Lee, Sung-Hee. Changes in Korean society and nursing care. Online available at:http://www.ilcjapan.org/chojuGIJ/pdf/18 03 2.pdf\#search='\%E9\%9F\%93\%E5\%9B $\% \mathrm{BD}+\% \mathrm{E} 4 \% \mathrm{BB}$ $\% 8 \mathrm{~B} \% \mathrm{E} 8 \% \mathrm{AD} \% \mathrm{~B} 7+\% \mathrm{E} 6 \% \mathrm{AD} \% \mathrm{BB} \% \mathrm{E} 4 \% \mathrm{BA} \% \mathrm{~A} 1 \% \mathrm{E} 3 \%$ $81 \% \mathrm{AE} \% \mathrm{E} 5 \% \mathrm{~A} 0 \% \mathrm{~B} 4 \% \mathrm{E} 6 \% 89 \% 80$

[9] M. Goto, A. Mikami, K. Mase, T. Tsukamoto. Views of elderly care staff on terminal care and death, Kousei no Shihyou, Vol. 61, No. 15, 28-34, 2014.

[10] Online Available from International Longevity Center Japan: http://www.ilcjapan.org/symposium/doc/1202_03.pdf

[11] M. Goto, N. Morita, F. Katagiri, T. Tsukamoto. Current and future end-of-life care for the elderly in Japan and Korea: survey of staff at nursing care facilities and offices, Bulletin of Social Medicine, Vol. 31, No. 2, 151-158, 2014. 